\title{
Anatomy of the digestive tube of sea turtles (Reptilia: Testudines)
}

\author{
Marcela dos S. Magalhães ${ }^{1,4}$, Armando J. Barsante Santos ${ }^{2}$, \\ Naisandra B. da Silva ${ }^{3} \&$ Carlos E. B. de Moura ${ }^{3}$
}

\author{
1 Departamento de Morfologia, Laboratório de Histologia, Universidade Federal do Amazonas. Avenida General Rodrigo \\ Octávio Jordão Ramos 3000, 69080-005 Manaus, AM, Brazil. \\ 2 Fundação Pró-Tamar. Alameda do Boldró, 53990-000 Fernando de Noronha, PE, Brazil. \\ ${ }^{3}$ Departamento de Morfologia, Universidade Federal do Rio Grande do Norte. Campus Universitário Lagoa Nova, \\ Caixa Postal 1524, 59072-970 Natal, RN, Brazil. \\ ${ }^{4}$ Corresponding Author. E-mail: marcelasmbio@gmail.com
}

\begin{abstract}
This study characterized the morphology of the digestive tube of five species of sea turtles. We used specimens found dead along the coast of the state Rio Grande do Norte, as well as specimens accidentally killed as a result of pelagic longline fishing. Nineteen animals of the following species were analyzed: Chelonia mydas (Linnaeus, 1758) $(n=$ 9), Lepidochelys olivacea (Eschscholtz, 1829) $(n=6)$, Caretta caretta (Linnaeus, 1758) $(n=2)$, Eretmochelys imbricata (Linnaeus, 1766) $(n=1)$ and Dermochelys coriacea (Vandelli, 1761) $(n=1)$. After opening the plastron, we removed the digestive organs and described the external and internal morphology of each organ. The esophagus of all species had pointed papillae on the mucosa. The stomach varied in shape among species. Differences were found in the mucosa of the small intestine. It was reticular in the duodenum, and longitudinal rectilinear in the jejunum/ileum. In all species an alternation of saccular and narrow regions was observed in the large intestine. The exception was $D$. coriacea, in which the mucosa of the entire large intestine had irregularly distributed folds. The pattern of the esophagus was the same in all species. The morphology of the stomach differed among species, and these differences reflect their diets. In addition, the distribution pattern of the folds on the mucosa of the small intestine varied between regions of the intestine and among species.
\end{abstract}

KEYWORDS. Anatomy; digestive system; morphology.

Five species of sea turtles are found along the Brazilian coast: green turtle, Chelonia mydas (Linnaeus, 1758); hawksbill turtle, Eretmochelys imbricata (Linnaeus, 1766); olive ridley, Lepidochelys olivacea (Eschscholtz, 1829); loggerhead, Caretta caretta (Linnaeus, 1758); and leatherback, Dermochelys coriacea (Vandelli, 1761) (MARCovaldi \& Marcovaldi 1985). Each species has distinct alimentary habits, and some may have different diets according to their pelagic and/or benthic phase. Some species feed on jellyfish or oceanic fish, whereas others are herbivores and consume gramineous plants and sea algae along coastal regions (Pereira \& SOARES-Gomes 2002). Under natural conditions, C. caretta and D. coriacea are carnivorous, E. imbricata, and L. olivacea are omnivorous, and C. mydas is the only herbivorous species of sea turtle (BJORNDAL 1997, BRANDGardner et al. 1999, Chevalier \& Lartiges 2001).

Several anthropogenic impacts such as predatory fishing, habitat destruction, intervention on nesting beaches, and sea pollution (mainly synthetic garbage and oil spills) (CARR 1987, Bugoni et al. 2001) are responsible for the disappearance of many populations of sea turtles in the recent decades, despite protective laws and the activities of some national projects such as TAMAR/ICMBio, which work toward the conservation of sea turtles and environmental education in Brazil.

All knowledge about the biology of the species in question is of great importance for the protection and conservation of sea turtle populations. Biological and ecological studies on sea turtles have been growing significantly; however, not many studies have been conducted on the anatomy of the digestive tube of these species.

Some authors (PARSONs \& CAMERON 1977, RaINEY 1981, Work 2000, WyneKen 2001, Pressler et al. 2003, MagalHães et al. 2010) describe that the esophagus of sea turtles is generally covered with pointed and keratinized papillae, the stomach is curved and situated to the left of the coelomic cavity, and its mucosa is generally folded. The lining of the small intestine is textured and, in many species, it is "honey-combed" in appearance. The large intestine is divided into the cecum, the colon and the rectum. The cecum is the most proximal region. The largest portion is the colon and there, distally, a narrowing occurs, forming the rectal muscle. According to WYNEKEN (2001), the length of the gut is somewhat related to the animal's diet, being proportionally longer in green and leatherback turtles than in loggerheads, ridleys, and hawksbills. 
The morphology of the digestive tract is related to its digestive function. It is possible to diagnose the diet of a species by studying anatomical and physiological differences of the digestive tube. This is evident when the various kinds of stomachs or intestines with differing lengths are observed, and occasionally, these structures can be used in systematics (Godinho 1970, Hildebrand \& Goslow 2006).

Anatomical studies provide essential information for the clinical treatment of wild animals, these studies can be performed on chelonians and are associated with additional tests such as endoscopy, colonoscopy, ultrasound imaging and radiography (VALENTE et al. 2007). The objective is to elucidate physiological and pathological phenomena of the gastrointestinal tract (Holt 1978, Meyer 1998), including, but not limited to, gastroenteric obstructions by foreign bodies. The chelonian gastrointestinal tract is anatomically diverse and endoscopic examination techniques will probably vary between species. The wide variety of reptiles demands efforts to understand particular features of the normal anatomy of species of economic and conservational interest (CosTA et al. 2009). Moreover, morphological studies on the digestive tract of sea turtles may produce information that will enable comparative analyses with other chelonians, and also provide insights for future evolutionary studies on the group, especially those regarding adaptations related to feeding habits.

The objective of the present study was to characterize the macroscopic morphology of the digestive tube of five sea turtle species in order to understand the physiology of digestion in these species.

\section{MATERIAL AND METHODS}

Sea turtles used in this study were sea turtles found dead along the coast of Rio Grande do Norte state, Brazil, as well as those killed accidentally through the practice of pelagic longline fishing, between January 2006 and October 2007, and were donated to the project TAMAR/ICMBio (License N.006/05 IBAMA-RN). Individual data on the curvilinear length of the carapace (CLC) was performed on all specimens. Nineteen animals were examined: nine C. mydas $(36.91 \pm 8.10 \mathrm{~cm})$, six $L$. olivacea $(45.07 \pm 7.18 \mathrm{~cm})$, two C. caretta $(90.65 \pm 3.32 \mathrm{~cm})$, one D. coriacea $(135.00 \mathrm{~cm})$, and one E. imbricata $(36.20 \mathrm{~cm})$.

The animals were dissected according to the methodology proposed by Work (2000), allowing analysis of external and internal morphological characteristics of the digestive tube. Examination of the digestive organs (esophagus, stomach, small intestine and large intestine) was carried out through the opening of the plastron, with subsequent removal of the pectoral muscles, pelvic girdle and clavicles.

The anatomical position of the animal was considered for descriptions of external morphology and visceral topography in the coelomic cavity. For the study of the internal morphology, the digestive tube was removed, opened and immersed in tap water, and food particles were removed to facilitate observation. Then, macroscopic morphological descriptions were performed for each internal organ, observing the presence and shape of papillae, type and arrangement of mucosal folds, and presence of sphincters. A flexible line was placed along each organ (esophagus, stomach, small intestine and large intestine) and then placed over a measuring tape to determine the length. Photographic images were taken to support the descriptions.

\section{RESULTS}

The esophagus of the species analyzed consisted of a tubular muscle-membranous organ, located medially at the cervical region; it deviates laterally to the left in the coelomic region, where it meets the cardiac region. The average length of the esophagus of each species is given below: C. mydas (19.32 $\pm 4.09 \mathrm{~cm}, \mathrm{n}=9)$, L. olivacea $(22.43 \pm 6.03 \mathrm{~cm}, \mathrm{n}=6)$, C. caretta $(24.35 \pm 6.57 \mathrm{~cm}, \mathrm{n}=2)$, and E. imbricata $(16.00 \mathrm{~cm}, \mathrm{n}=1)$. In D. coriacea the esophagus is exceptionally long $(167.00 \mathrm{~cm}, \mathrm{n}=$ 1) and extends through almost half the length of the body; it then loops to the left and joins the stomach.

In all species the esophageal mucosa was characterized by pointed papillae along its entire length (esophageal papillae); these papillae are oriented toward the stomach, and become progressively larger toward the caudal region of the esophagus (Figs 1 and 2).

A narrowing of the muscle was observed at the limit of the transition between the esophagus and the stomach. This transition is marked internally by the absence of papillae and by the gastroesophageal sphincter (Fig. 1). However, in this region, a pouch-shaped region was observed in two specimens of C. mydas, characterizing an esophageal diverticulum. The mucosa of the esophageal diverticulum lacked esophageal papillae (Fig. 3).

The stomach of all examined species was located on their left side.

In C. mydas, L. olivacea and E. imbricata, from the caudal portion of the esophagus, the stomach is curved to the left side forming initially the cardiac region, then a large pouch, the fundic region, and finally ascending to the right, forming the pyloric region. The stomach is J-shaped, with the characteristic of a bag with a dead end (Fig. 4). Internally, the mucosa of the stomach is characterized by longitudinal folds. When the stomach is distended, the folds disappear, giving the impression of being an organ without mucosal folds, as observed in some animals analyzed.

The stomach of C. caretta presented a curved tubular form on the left side of the animal, and then moved slightly to the right forming the first intestinal loop. The stomachs of the two specimens studied differed. In one animal the cranial and caudal regions presented sacculations, both devoid of mucosal folds, whereas the intermediate portion of the stomach was larger and marked by longitudinal folds (Figs 5 and 6). By contrast, the other animal did not present sacculations in the stom- 


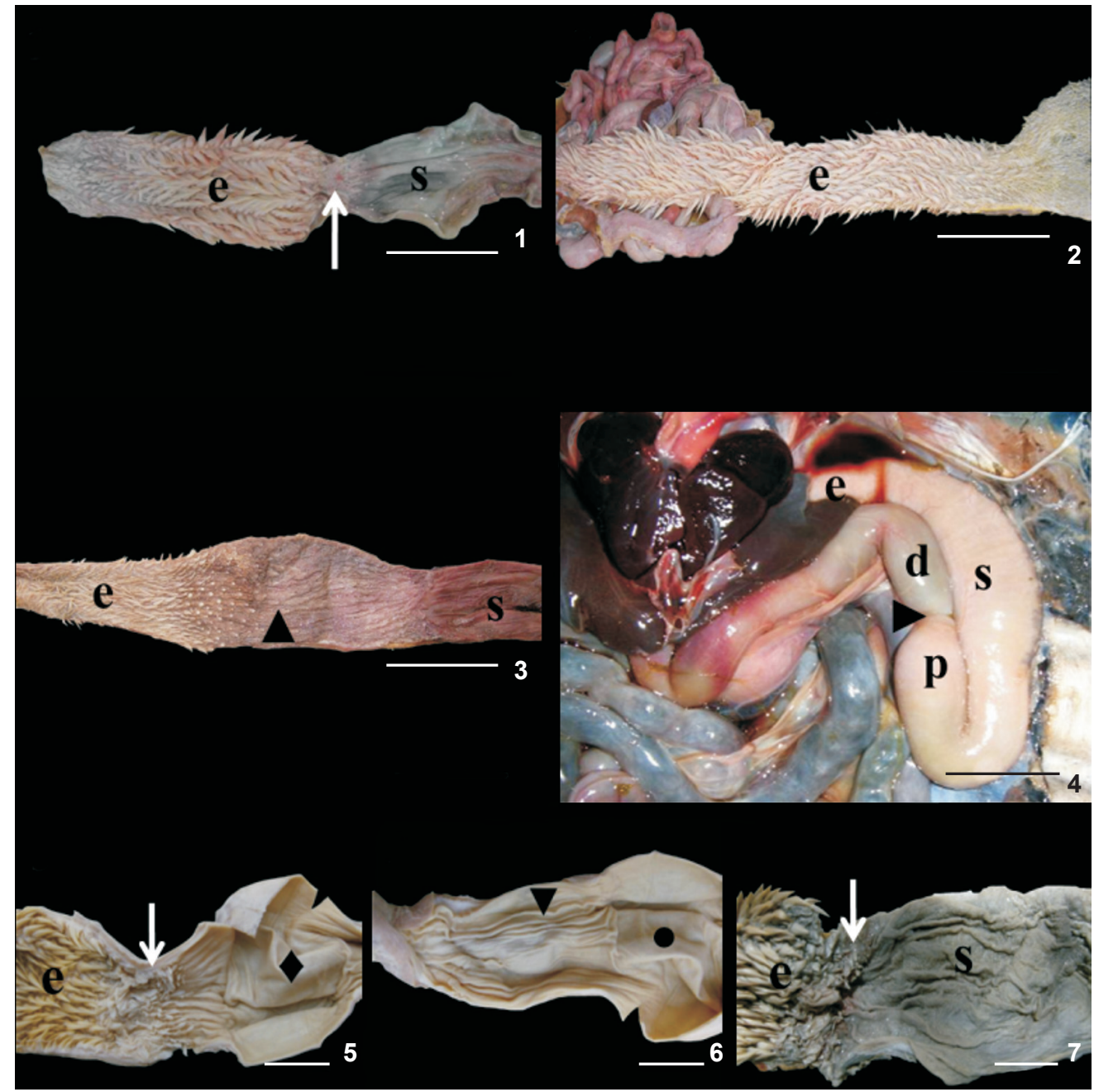

Figures 1-7. Morphology of the digestive tube in sea turtles: (1) esophageal mucosa with esophageal papillae found in all analyzed species; (2) esophageal mucosa with esophageal papillae in D. coriacea; (3) esophageal diverticulum found in two specimens of $C$. mydas; (4) stomach J-shaped in C. mydas; (5-6) different pattern found in the stomach of another specimen of $C$. caretta. Presence of a sacculation devoid of folds in the cranial region $(\bullet)$ and caudal region $(\bullet)$; intermediate portion with longitudinal folds $(\boldsymbol{\nabla})$. (7) stomach with folded mucosa found in one specimen of C. caretta. (e) Esophagus; (s) stomach; $(\rightarrow)$ gastroesophageal sphincter; $(\mathbf{\Delta})$ esophageal diverticulum; (p) pyloric region; $(\triangleright)$ pyloric sphincter; (d) duodenum. Scale bars: $5 \mathrm{~cm}$.

ach, and longitudinal folds were observed along the entire mucosa (Fig. 7).

The stomach of $D$. coriacea was also curvilinear and tubular. The regions of the stomach were characterized and differentiated by their mucosa. The wall of the cranial region was thinner than in other regions, and had longitudinal mucosal folds (Fig. 8). The middle region, which is the largest portion of the organ, had a thick wall and a mucosa formed by large transverse folds (Fig. 9). The distal region, which is the smaller portion of the organ, was globular, with a thin wall and mucosa without folding pattern (Fig. 10).
The lengths of the stomachs of the different species analyzed were: $C$. mydas $(22.37 \pm 9.08 \mathrm{~cm}, \mathrm{n}=9)$, L. olivacea $(36.56$ $\pm 9.80 \mathrm{~cm}, \mathrm{n}=6)$, C. caretta $(43.10 \pm 1.55 \mathrm{~cm}, \mathrm{n}=2)$, E. imbricata $(27.70 \mathrm{~cm}, \mathrm{n}=1)$ and $D$. coriacea $(162.80 \mathrm{~cm}, \mathrm{n}=1)$.

Internally the transition between the stomach and the duodenum was characterized by a pyloric sphincter with mucosa presenting longitudinal folds in C. mydas, L. olivacea, E. imbricata and $D$. coriacea. The sphincter in C. caretta was not evident, and its transition was characterized by alterations of the mucosa of the stomach from longitudinal folds to reticular folds in the small intestine. 


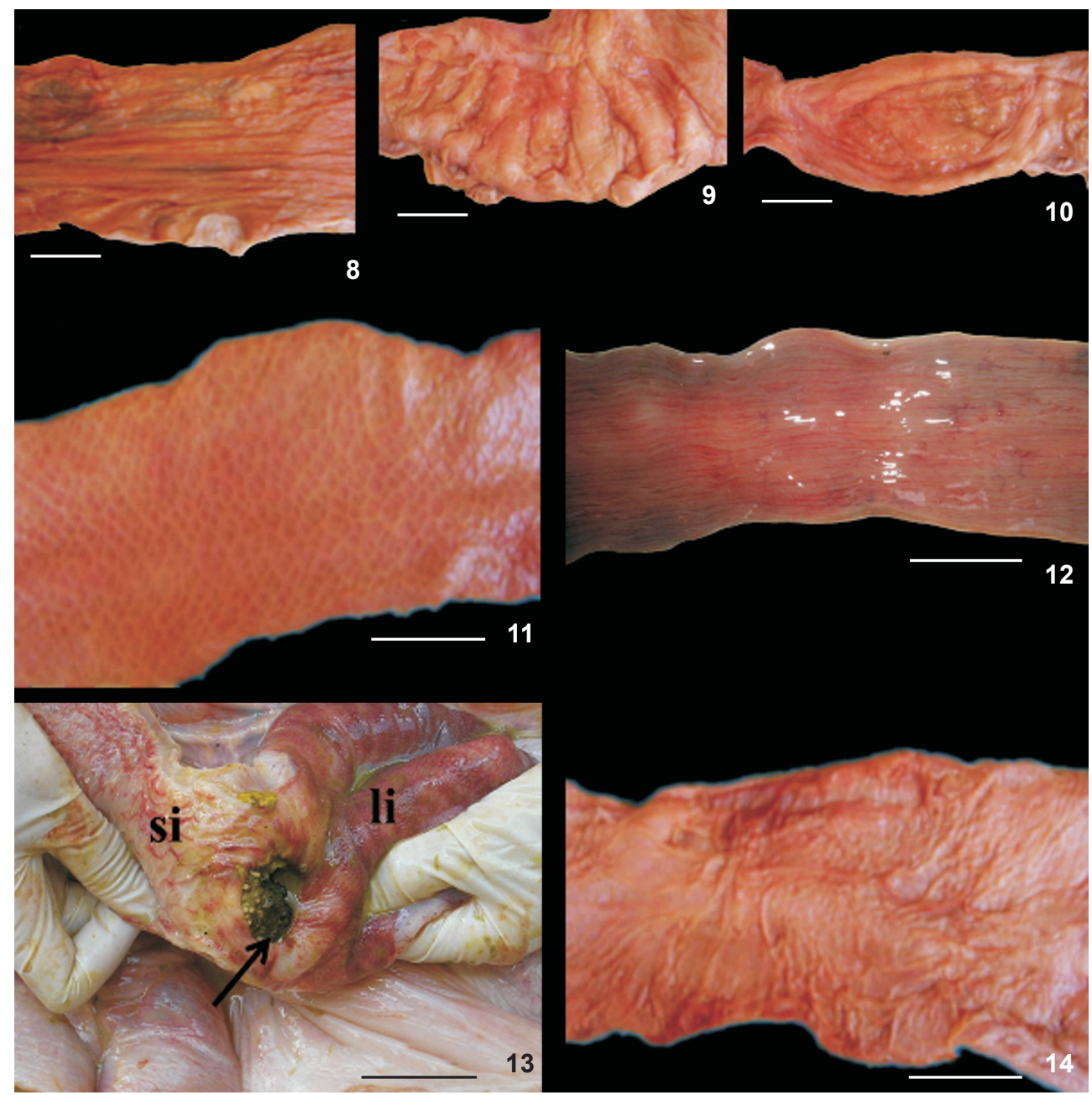

Figures 8-14. (8) Mucosa of the cardial cardiac region in D. coriacea with longitudinal folds; (9) mucosa of the fundic region in $D$. coriacea with large transversal folds; (10) Note absence of folds in the pyloric region in $D$. coriacea; $(11)$ mucosa of duodenum with presence of reticular folds in a "honey-combed" arrangement in D. coriacea; (12) mucosa of jejunum/ileum with rectilinear folds in C. mydas; (13) small lateral pouch extending from the side wall next to the ileocecal sphincter $(\rightarrow)$ in $D$. coriacea, small intestine (si), large intestine (li); (14) mucosa of the large intestine in $D$. coriacea marked by folds with irregular distribution. $S$ cale bar: $5 \mathrm{~cm}$.

In all examined species the small intestine (SI) consisted of a long and convoluted tube with a constant diameter throughout its length. The first intestinal loop originates from the pyloric sphincter, as a region that curves upward from left to right. Then, it descends slightly, becoming an entangled organ located medially in the coelomic cavity. The first shorter region, soon after the pyloric sphincter, was considered the duodenum; and the longer and more coiled region was considered the jejunum/ileum, because the transition between the jejunum and ileum could not be determined. In C. mydas, $L$. olivacea, C. caretta and E. imbricata mucosa of the duodenum was characterized by the presence of reticular folds. The jejunum/ileum region had rectilinear longitudinal folds (Fig. 12).
However in D. coriacea the small intestine had reticular folds in a pattern similar to a "honey-combed" throughout its length (Fig. 11), and it was not possible to identify the limits of each region of the small intestine.

The SI presented the following average lengths: C. mydas $(145.13 \pm 16.52 \mathrm{~cm}, \mathrm{n}=9)$, L. olivacea $(231.08 \pm 25.39 \mathrm{~cm}, \mathrm{n}=$ 6), C. caretta $(350.10 \pm 54.00 \mathrm{~cm}, \mathrm{n}=2)$, E. imbricata $(160.12$ $\mathrm{cm}, \mathrm{n}=1)$ and $D$. coriacea $(592.00 \mathrm{~cm}, \mathrm{n}=1)$.

The transition from the small to the large intestine was characterized by an ileocecal sphincter in all species studied. However, in $D$. coriacea a small lateral pouch extending from the side wall next to the ileocecal sphincter was present (Fig. 13). Regions of the large intestine (LI) were difficult to identify 
macroscopically due to the absence of defined limits. In $C$. mydas, L. olivacea, E. imbricata and C. caretta the LI was identified by the alternation of saccular and narrow regions. The saccular regions had a smooth mucosa, probably because of the accumulation of feces, and a narrow region with rectilinear folds. The caudal region, near the cloaca, was characterized by evident rectilinear folds. In $D$. coriacea, the LI had irregularly distributed mucosal folds along its entire length (Fig. 14).

The average lengths of the LI were as follows: C. mydas $(238.43 \pm 24.99 \mathrm{~cm}, \mathrm{n}=9)$, L. olivacea $(166.05 \pm 17.93 \mathrm{~cm}, \mathrm{n}=$ 6), C. caretta $(265.75 \pm 25.50 \mathrm{~cm}, \mathrm{n}=2)$, E. imbricata $(167.50$ $\mathrm{cm}, \mathrm{n}=1)$ and D. coriacea $(158.00 \mathrm{~cm}, \mathrm{n}=1)$.

\section{DISCUSSION}

The gastrointestinal tract is marked by structural and functional divisions (WyneKen 2001). Comparative studies indicate that differences exist in the structure and function of digestive tubes among carnivores, omnivores and herbivores, and that morphological variations are governed by differences in diet (Grady et al. 2005).

The morphology of the digestive tube of sea turtles is adapted to the feeding habits of the species. These adaptations were evident even in the esophagus, which had a mucosa marked by conical papillae and was oriented toward the stomach. The esophageal papillae had already been described for sea turtles by Porter (1972), Work (2000), Wyneken (2001), Pressler et al. (2003), and Magalhães et al. (2010). The orientation pattern of esophageal papillae suggests that they perform the functions of facilitating the intake of food and avoiding regurgitation caused by the changes of pressure during diving (Bleakney 1965). According to Wyneken (2001), the esophagus conveys food to the stomach and expels excess water. Microscopic analysis of the esophageal mucosa of C. mydas also revealed adaptations such as a keratinized squamous epithelium, which most likely confer protection against the friction generated by the passage of food. Moreover, the absence of glands corroborates the fact that this organ is only related to the transport of food to the stomach (MAGalHães et al. 2010).

The presence of sacculations in the caudal region of the esophagus characterizing an esophageal diverticulum was observed in two specimens of C. mydas. This structure was also observed by Work (2000) and WyNEKEN (2001) for green turtles in Hawaii and the Pacific. It was described as having the function of storing food before passing into the stomach, as well as keeping food in the digestive tube for longer periods to allow for better digestion. Furthermore, the presence of sacculation in the esophagus could be associated with a fermentation chamber in herbivorous species.

According to WyNeken (2001) the chemical and physical process of digestion begins in the stomach. The findings regarding the stomach of these animals revealed variations between species, which reflect adaptations to their diets. In $C$. mydas, L. olivacea and E. imbricata, the stomach was J-shaped, and the mucosa was characterized by longitudinal folds. This same pattern of folds had already been described by Parsons \& CAMERon (1977) for C. mydas, and by Work (2000) for sea turtles in general. The stomachs of C. caretta had two patterns: tubular with longitudinal folds, as described by RaINEY (1981); or with a sacculation in the cranial and caudal regions. Those sacculations had not been previously described. More studies are needed to identify the function of this saccular region in $C$. caretta, a carnivorous species. In addition, more specimens should be examined, and histological examinations in particular would be useful to verify the most frequent pattern in the stomachs of this species.

According to RaINey (1981), the stomach of D. coriacea has two distinct parts: a globular anterior chamber and a tubular posterior segment, which is partly subdivided into smaller chambers by about twelve transverse ridges. His description differs from our findings: in the specimens we analyzed, three distinct regions were identified in the stomach: the cranial region with longitudinal mucosal folds, the middle region with thick wall formed by large transverse folds, and the distal region without a folds pattern. The longitudinal folds probably allow the free passage of food items through the lumen, where it can be restricted by transverse or oblique folds (PARSONS \& CAMERON 1977).

In C. mydas, L. olivacea, E. imbricata and D. coriacea, a small muscular region was identified in the transition from the stomach to the small intestine, characterizing a pyloric sphincter. The sphincter was not evident only in C. caretta, and the transition was identified by a change in the mucosa, from the large longitudinal folds of the stomach to a "network" of zigzag folds in the small intestine, as previously described by RAIney (1981).

The presence of folds in the small intestine was described for several species of turtles (Parsons \& Cameron 1977, Legler 1993, Work 2000, Wyneken 2001). Work (2000) and Wyneken (2001) reported that the entire mucosa of the small intestine had "honey-combed" reticular folds. These authors probably based their conclusions on a general description, with no details on each species. Among the species analyzed, variations in the distribution pattern of the mucosal folds in different regions of the small intestine were observed. To define each region of the small intestine properly, histological methods should be used, because each region is characterized by different villi and folds. In the small intestine, digestive enzymes are added to food to break down proteins and complex carbohydrates. The small intestine is regionally specialized to absorb amino acids, carbohydrates, sugars, water, fatty acids, and minerals (particularly calcium and phosphorus) (WYNEKEN 2001). The presence of folds considerably enlarges the surface of this organ, thus increasing the area available for absorbing nutrients (Porter 1972, Romer \& Parsons 1985, Legler 1993, Wyneken 2001). 
In all examined species the small intestine was separated from the large intestine by a muscular sphincter named by Porter (1972), Rainey (1981) and Wyneken (2001) as the ileocecal valve. However, in $D$. coriacea a small lateral pouch was observed, extending from the large intestine wall near the valve. The finding was also observed in this species by RaINEy (1981), which he called the cecum. But a specific function was not given for this structure and therefore more studies are needed, including histological analysis.

The digestive importance of the large intestine varies according to the species. In carnivores, it is where the recuperation of water occurs. In herbivores, the cecum is of great importance. Besides being the location in which recuperation of water occurs, it is also where bacterial digestion of cellulose and other carbohydrates from plant materials takes place (Hildebrand \& Goslow 2006). In the large intestine of the species C. mydas, L. olivacea, E. imbricata and C. caretta, regions with flat mucosa were observed, probably due to the accumulation of fecal matter. By contrast, in D. coriacea the presence of mucosal folds was evident. Work (2000) describes the mucosa of the large intestines in sea turtles is smooth. According to Parsons \& Cameron (1977), the pattern in the colon is very difficult to describe because it is rarely distinct. Furthermore, because the colon is extendable, the pattern of folds may completely disappear when it is full. The main conclusions of this study can be summarized as follows: 1) All species of sea turtle have esophageal mucosa marked by pointed papillae oriented toward the stomach. 2) An esophageal diverticulum was observed in C. mydas, an herbivorous species. This is likely related to the need to keep the food for longer in this organ in order to allow for a more efficient digestion. 3) The morphology of the stomach varied among species and is related to their diets. In C. mydas, L. olivacea and E. imbricata it is J-shaped, sacculiform and dead-ended; in D. coriacea it is curved and tubular; the stomach of $C$. caretta is tubular, and variations were observed in the two specimens studied. Further studies are necessary to verify this pattern and also to explain the variations. 4) The distribution pattern of the mucosal folds of the small intestine varied between the regions of the intestine and among species.

\section{LITERATURE CITED}

BJORNDAL, K.A. 1997. Foraging ecology and nutrition of sea turtles, p. 199-231. In: P.L. Lutz \& J.A. Musick (Eds). The Biology of Sea Turtles. Florida, CRC Marine Sciences Series, 407p.

BLEAKNEY, J.S. 1965. Reports of marine turtles from New England and Eastern Canada. Canadian Field-Naturalist 79: 120128.

Brand-Gardner, S.J.; J.M. Lanyon \& C.J. Limpus. 1999. Diet selection by immature green turtles, Chelonia mydas, in subtropical Moreton Bay, south-east Queensland. Australian Journal of Zoology 47: 181-191.
Bugoni, L.; L. Krause \& E.M.V. Petry. 2001. Marine debris and human impacts on sea turtles in southern Brazil. Marine Pollution Bulletin 41: 1338-1342.

CARR, A. 1987. Impact of non-degradable marine debris on the ecology and survival outlook of sea turtles. Marine Pollution Bulletin 18: 352-356.

Chevalier J. \& A. Lartiges. 2001. Les Tortues Marines des Antilles. Ed. Office National de La Chasse et de la Faune Sauvage. Paris, CNERA Faune d'Outre Mer, 59p.

Costa, F.B.; F.R. Alves; A.P. Costa; A.C.E. Barros; A.L. Sousa \& A.S. OliveIRA. 2009. Ultrasonographic and radiographic determination of egg development of jurarás (Kinosternon scorpioides) in captivity. Pesquisa Veterinária Brasileira 29 (10): 841-846.

Godinho, H.; M. Tokumaru \& A.G. Ferri. 1970. Histologia do tubo digestivo de Pimelodus maculatus Lacepede (Pisces, Siluroidei). Revista Brasileira de Biologia 30 (4): 583-593.

Grady, S.P.O.; M. Morando; L. Ávila \& M.D. Dearing. 2005. Correlating diet and digestive tract specialization: Examples from the lizard family Liolaemidae. Zoology 108 (3): 201-210.

Hildebrand, M. \& G.E. Goslow. 2006. Análise da Estrutura dos Vertebrados. São Paulo, Atheneu, 637p.

Holt, P.E. 1978. Radiological studies of the alimentary tract in two Greek tortoises (Testudo graeca). Veterinary Record 103 (10): 198-200.

Legler, J.M. 1993. Morphology and Physiology of the Chelonia, p. 108-119. In: C.J. Glasby; G.J.B. Ross \& P.L. BeEsley (Eds). Fauna of Australia. Caberra, Australian Biological Resourses Study, 439p.

Magalhães, M.S.; M.L. Freitas; N.B. Silva \& C.E.B. Moura. 2010. Morfologia do tubo digestório da tartaruga verde (Chelonia mydas). Pesquisa Veterinária Brasileira 30 (8): 676-684.

Marcovaldi, M.A. \& G.G. Marcovaldi. 1985. Projeto Tamar: area de desova, ocorrência e distribuição das espécies, época de reprodução, comportamento de postura e técnicas de conservação das tartarugas marinhas no Brasil. Brasília, MA-IBDF, 46p.

Meyer, J. 1998. Gastrografin as a gastrointestinal contrast agent in the Greek tortoise (Testudo hermani). Journal of Zoo and Wildlife Medicine 29 (2): 183-189.

Parsons, T.S. \& J.E. Cameron. 1977. The internal relief of the digestive tract, p. 159-223. In: G. Gans \& T.S. Parsons (Eds). Biology of the Reptilia. New York, Academic Press, 505p.

Pereira, R.C. \& A. Soares-Gomes. 2002. Biologia marinha. Rio de Janeiro, Interciencia, 382p.

Porter, K.R. 1972. Herpetology. Canada, W.B. Saunders Company, 530p.

Pressler, B.M.; R.A. Goodman; C.A. Harms; E.C. Hawkins \& G.A. LEwBart. 2003. Endoscopic evaluation of the esophagus and stomach in three loggerhead sea turtles (Caretta caretta) and a malaysian giant turtle (Orlitia borneensis). Journal of Zoo and Wildlife Medicine 34 (1): 88-92.

Rainey, W.E. 1981. Guide to Sea Turtle Visceral Anatomy. Berkeley, Museum of Vertebrate Zoology, University of California, NOAA Technical Memorandum NMFS-SEFC, 80p. 
Romer, A.S. \& T.S. Parsons. 1985. Anatomia Comparada dos Vertebrados. São Paulo, Atheneu, 559p.

Valente, A.L.; M.L. Parga; Y. Espada; S. Lavin; F. Alegre; I. Marco $\&$ R. CuENCA. 2007. Ultrasonographic imaging of loggerhead sea turtle (Caretta caretta). Veterinary Record 161: 226-232.

Work, T.M. 2000. Manual de Necropsia de Tortugas Marinas

Submitted: 22.VI.2011; Accepted: 08.II.2012.

Editorial responsibility: Carolina Arruda Freire para Biologos en Refugios o Areas Remotas. Hawaii, U.S. Geological Survey National Wildlife Health Center, Hawaii Field Station, 25p.

Wyneken, J. 2001. The Anatomy of Sea Turtles. Washington, D.C., US Department of Commerce, NOAA Technical Memorandum NMFS-SEFSC-470, 172p. 